\title{
TREATMENT OF ENCEPHALOTRIGEMINAL ANGIOMATOSIS (STURGE-WEBER DISEASE) BY HEMISPHERECTOMY
}

\author{
BY \\ M. A. FALCONER and R. G. RUSHWORTH
From the Guy's-Maudsley Neurosurgical Unit, London
}

(RECEIVED FOR PUBLICATION DECEMBER 17, 1959)

Encephalotrigeminal angiomatosis or SturgeWeber's disease is an uncommon congenital disorder which can vary greatly in the extent of its manifestations, but which in severe cases can lead to infantile hemiplegia associated with fits, behavioural disorders and mental backwardness. Until comparatively recently specific therapy was largely limited to anticonvulsant drugs. Only a few isolated reports of surgical intervention have been recorded. The purpose of this paper therefore is to describe the findings and results of surgery in five consecutive patients with infantile hemiplegia treated by hemispherectomy and since followed up for from three to eight years who improved as regards epilepsy and personality disorders, although not as regards hemiplegia. A preliminary report on the first two of these cases has already been presented (Polani, 1952).

Excellent reviews of the clinical manifestations and pathogenesis of the condition have recently been given by several authors (Medoc, Sotelo, Arana Iñiquez and Estable Puig, 1953-1954; Lichtenstein, 1954; Wohlwill and Yakovlev, 1957; Norman, 1958; Peterman, Hayles, Dockerty and Love, 1958). The essential lesion appears to be a venous angiomatosis of the leptomeninges generally over one cerebral hemisphere, most often in the posterior parietal and occipital regions, associated with a port-wine naevus of the skin of the face in the territory of one or more divisions of the trigeminal nerve, on the same side of the body. Occasionally both cerebral hemispheres are involved, and the cutaneous naevus may also be in other parts of the body. In all cases the affected areas of cortex become atrophic with the deposition of calcium and ferruginous materials that give rise to a characteristic curvilinear appearance on radiographs. Other lesions that may be present include angioma of the choroid of the eye and ipsilateral buphthalmos or glaucoma. Dural and diploic vascularity is exceptional.

The first recorded case description is that of
Rudolf Schirmer (1860) who described a 36-year-old patient with an extensive naevus involving both sides of the face, left more than right, as well as the chest and abdomen. He did not mention any neurological features, but pointed out that the patient's left eye protruded, and that there was hydrophthalmos and varicosities of the retinal veins. Allan Sturge (1879) demonstrated to the Clinical Society of London a girl of $6 \frac{1}{2}$ years of age who had an extensive 'port-wine mark' over the right side of the head and face with enlargement of the right eye and vascular changes in the choroid. He inferred that her left-sided fits were caused by a similar vascular lesion of the right side of the brain. Kalischer (1897) gave the first autopsy report of this condition. He $(1897 ; 1901)$ described an extensive telangiectasis of the scalp and the surface of the brain, all on the same side. He did not, however, observe any calcification, presumably because his subject was only $1 \frac{1}{2}$ years old. Hebold (1913) was the first to note the cerebral calcification, but did not determine its precise situation. However, Weber $(1922 ; 1929)$ was the first to publish a radiograph of the double curvilinear shadows that outline the sulcal pattern, although according to Krabbe (1934) Wissing, in 1921, had demonstrated these features to the Radiological Society of Copenhagen. It was Krabbe (1934) himself who demonstrated that the calcium deposits occurred within the cortex and not in the angiomatous vessels. Dimitri (1923), from the Argentine, also published an early description of the radiological appearances.

By this time the essential features of the disease were all recorded, but there has been some difference of opinion over nomenclature. 'Sturge-Weber disease' or 'Sturge-Weber syndrome' have become sanctioned by usage, although Weber (1936) disclaimed the use of his name and suggested that it be called 'Sturge-Kalischer disease'. It has also been called 'Krabbe's disease', and 'Sturge-WeberDimitri disease' (Lichtenstein, 1954), and 'SturgeWeber-Krabbe's disease' (Krayenbühl, Yaşargil and 
Uehlinger, 1957). Of the non-eponymous terms 'encephalotrigeminal angiomatosis' or 'meningofacial angiomatosis' seem the most accurate. In making the diagnosis it must be remembered that, like most congenital malformations, the syndrome may be incomplete. It is therefore advisable to limit the definition of Sturge-Weber disease to cases showing at least two of the major signs, such as facial naevus combined with either intracranial angioma or with angioma of the choroid of the eye (Poser and Taveras, 1957; Norman, 1958).

This rules out many superficially allied conditions such as spinal cord angiomas with cutaneous naevi of metameric distribution, cutaneous naevi with cerebellar symptoms, and the familial non-calcifying meningeal angiomas (Norman, 1958), and also the cerebral calcification epilepsy of Geyelin and Penfield (1929).

\section{Technique of Hemispherectomy in Sturge-Weber Disease}

As all the cases in our series were operated upon in the same way, it will be convenient to outline the surgical technique used before proceeding to the case reports. To Krynauw (1950) must be given the credit for introducing, on a sound and systematic basis, the operation of hemispherectomy as a method of treating epilepsy and behavioural disorders in patients with infantile hemiplegia from various causes. The technique advocated by him, which has been followed by others (Cairns and Davidson, 1951; Gros, 1951; McKissock, 1953 and 1954), was to remove the cerebral hemisphere in segments. Obrador Alcalde (1950 and 1952), however, removed the affected cerebral hemisphere in one piece, and a similar technique was employed in all our cases. This technique stems from the original work of Dandy (1928), who first removed the cerebral hemisphere of a patient because of a glioma, and has since been adopted by others (Gros and Vlahovitch, 1954; French, Johnson, Brown and Van Bergen, 1955).

All our operations were performed under general anaesthesia without the use of hypothermia or of arterial hypotension. A large fronto-temporo-parietal craniotomy is turned extending medially from the midline to the floors of the anterior and middle cranial fossae laterally. The scalp incision is outlined in Fig. 5. Beneath it the bone flap is cut and pedicled on the temporal muscle. The dura is then opened in such a way that it can be sutured later. After the preliminary inspection of the hemisphere the first step in the excision is to elevate the frontal lobe and open up the inner part of the sylvian fissure so that the middle cerebral artery can be clipped and then divided just distal to its central perforating branches. This step lessens subsequent bleeding.

Attention is then turned to the region of the sagittal sinus, and the veins entering it from the superior margin of the hemisphere are coagulated and divided from before laterally. This enables the hemisphere to be retracted from the falx, exposing the mesial surface of the opposite cerebral hemisphere, the corpus callosum and the two anterior cerebral arteries. The ipsilateral anterior cerebral artery can then be divided a little distal to the anterior communicating artery, while the ipsilateral edge of the corpus callosum is then incised from its genu anteriorly to its splenium posteriorly so exposing the interior of the lateral ventricles. Retraction of the hemisphere permits the caudate nucleus to be identified, and separation of the hemisphere from the basal ganglia and thalamus is commenced by dividing the cerebral substance along the lateral edge of the nucleus towards its tail. This cut is extended until the temporal horn is laid open. The surgeon then returns to the genu and after dividing the rostrum of the corpus callosum, he divides the frontal cortex immediately in front of the chiasm and optic nerve, so opening into the cut through which the middle cerebral artery was severed. This is then extended subpially along the infero-medial temporal border removing the uncus and hippocampus, the free edge of the tentorium being followed, and the posterior cerebral artery being severed. The penultimate stage is now reached whereby the cortex and white matter of the isthmus of the limbic lobe is divided right through from the trigone of the lateral ventricle to the tentorial opening. The last stage of removal is undertaken by dividing the veins which pass from the occipital pole to the various venous sinuses. Finally, the choroid plexus is coagulated to prevent excessive cerebrospinal fluid formation, as so much of the absorbing area has been taken away with the resected hemisphere. The dura is then closed and the cavity filled with Ringer's solution. The bone and scalp flaps are replaced.

A blood transfusion is given during the operation. Recovery is usually rapid. The only complication encountered in this series was an indolent infection in Case 1 of the large dead-space between the sutured dura and the skull. This was controlled by antibiotics and eventually cured by removing a small sequestrum that had formed at the centre of the inner table of the skull. In two hemispherectomies for infantile hemiplegia for other lesions, one of us (M.A.F.) has also encountered the complication of a communicating hydrocephalus involving the operative cavity with the ventricular system and spinal subarachnoid space. It appears to be due to the brain-stem shift described by Cabieses, Jerí and Landa (1957), and in both cases was relieved by reopening the craniotomy and dividing the tentorium cerebelli so relieving the upward thrust of the midbrain and cerebellum. This complication occurred even though the choroid plexus had been coagulated.

Removal of the cerebral hemisphere in the manner described is no more difficult than the technique employed by Krynauw, and has the advantage of procuring a specimen that is intact.

\section{Case Reports}

Case 1. R.D., $3 \frac{1}{2}$ years of age, was referred by Dr. P. R. Evans. This boy was born with a left facial naevus. Seizures started at the age of 4 months, and were characterized by clonic movements of the right 
limbs, and deviation of the head and eyes to the right. At first they occurred in clusters every day for a week, followed by periods of freedom of up to four months, but later, in spite of intensive medication with phenobarbitone, potassium bromide and phenytoin, they occurred several times daily. Weakness of the right arm and an extensor plantar response were first noted when he was 13 months old, but radiographs of his skull at that time were reported to be normal, although encephalography showed a shrunken left hemisphere. An arteriogram was also said to be normal. There were no temper tantrums, but he was sullen, moody and irritable.

Examination. He was small, pallid and underdeveloped; he was very backward, and could only utter a few words; he understood simple commands and could point out objects. The naevus was patchy and involved the ophthalmic and maxillary divisions of the territory of the left trigeminal nerve (Fig. 1). No bruit

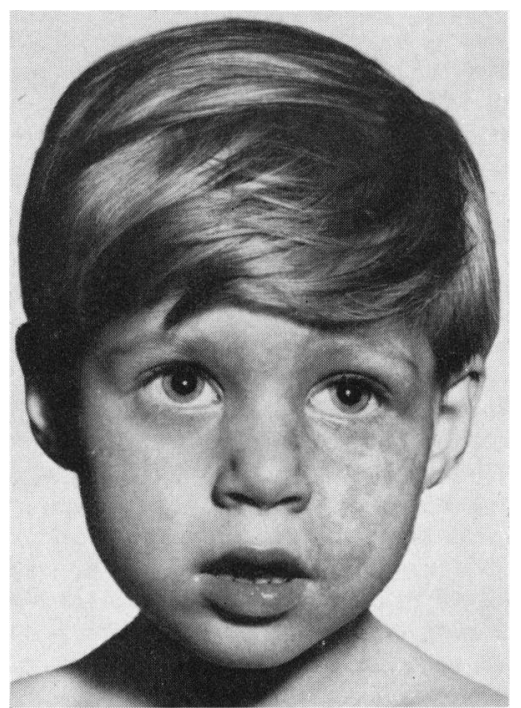

FIG. 1.-Case 1, before operation, showing characteristic naevus which has been partially bleached by past applications of carbon dioxide snow.

was heard over the skull. The optic fundi were normal. A right homonymous hemianopia was demonstrable by menace. There was a right-sided infantile hemiplegia characterized by some wasting and shortening of the limbs with spastic weakness; this weakness was slight in the lower face. Motor power at the shoulder and elbow was reduced about $50 \%$. He could grip feebly with his fingers, but could not extend his right wrist or fingers. The weakness was less obvious in his right leg where he could dorsiflex his ankles and move his toes. The tendon jerks were increased in right arm and leg, and the right plantar response was extensor. $\mathrm{He}$ responded equally to pinprick on both sides of the body. He walked only with great difficulty. The left limbs were normal.
INVESTIGATIONS. Skull radiographs showed gross reduction in size of the left half of the cranial cavity, while the sulcal pattern of practically the whole of the left cerebral hemisphere (except for the frontal region) was outlined by the characteristic double-paralleled, sinuous, curvilinear lines (Figs. 2 and 3). Pneumoencephalography showed that the ventricular system

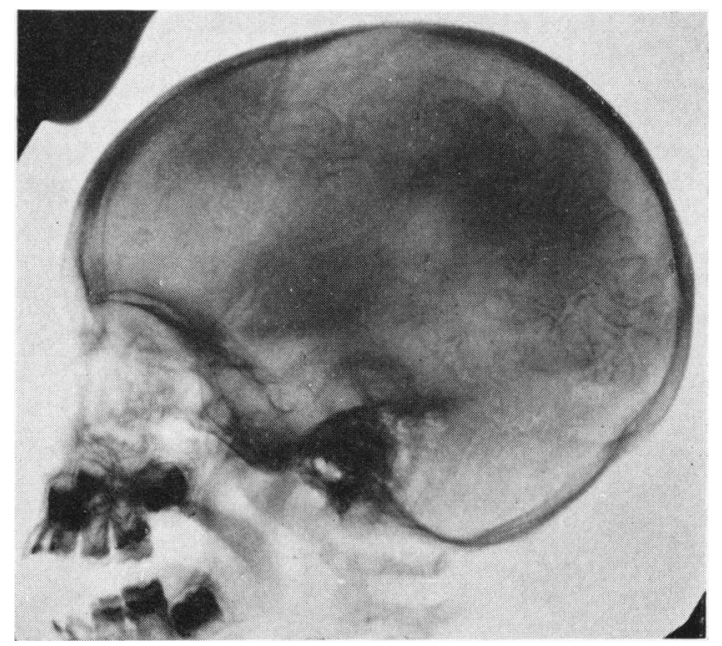

FIG. 2.-Case 1, straight lateral radiograph of skull, showing characteristic calcification.

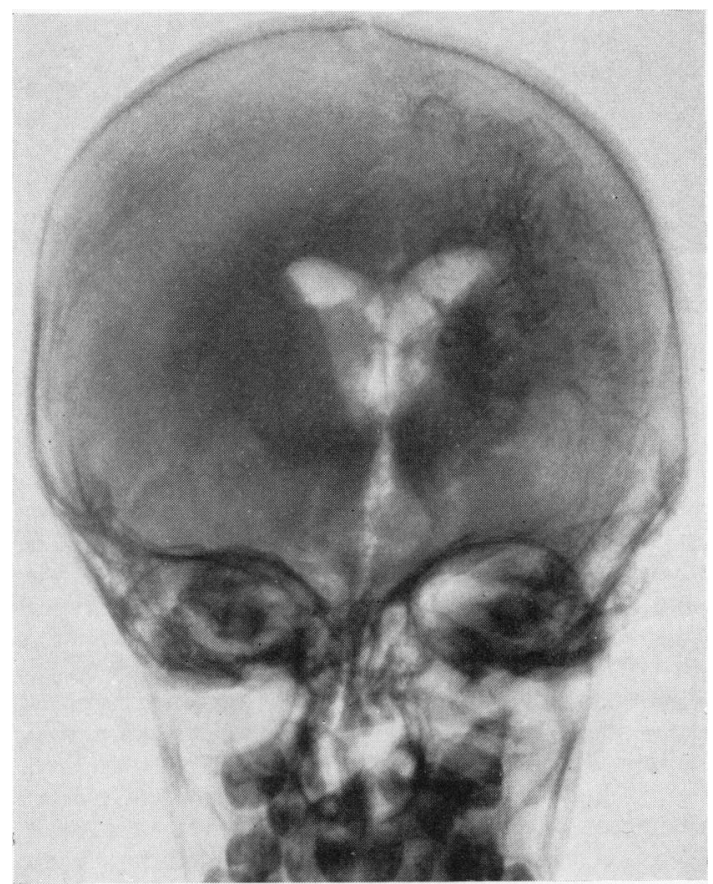

FIG. 3.-Case 1, antero-posterior air encephalogram, showing smallness of left cerebral hemisphere. 
was of normal size and shape, although displaced to the left because of the atrophy of its left cerebral hemisphere. Electroencephalography disclosed greatly diminished activity over the left cerebral hemisphere without definite spiking or other epileptic activity.

OPERATION. A large left-sided craniotomy was performed on August 15, 1951, under general anaesthesia. The whole convexity as seen through the craniotomy appeared red and congested with a fine network of small blood vessels closely meshed. These tiny blood vessels were in the subarachnoid space and they, together with cerebrospinal fluid, had elevated the arachnoid off the cortex so that at first the sulcal pattern could not be discerned (Fig. 4). When, however, the arachnoid

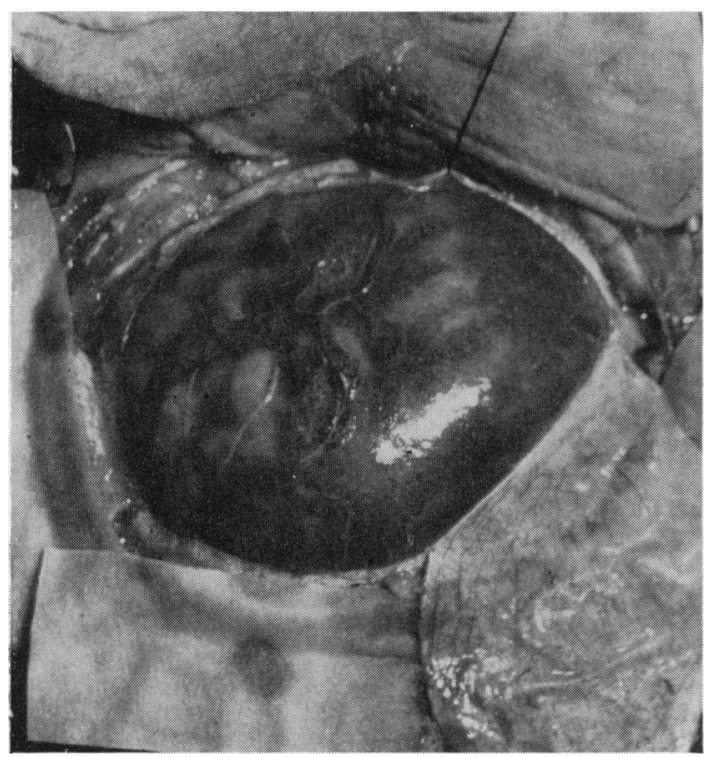

FIG. 4.-Case 1, operative appearances of left cerebral hemisphere as seen from the head of the operating table. Notice that whereas the pia-arachnoid alongside the superior longitudinal sinus is still lifted off the cortex, the convolutional pattern over the convexity of the cortex is becoming apparent as cerebrospinal fluid drains away from the sulci.

was pressed upon firmly with a glass slide, the subarachnoid spaces emptied so that one could see pale cortex between the interstices of the vascular network. The network itself did not blanch. Later this network was found to involve the whole surface of the left cerebral hemisphere on its medial and inferior aspects as well as over the convexity. The whole left hemisphere except for its thalamus and caudate nucleus was then removed in one piece. The patient stood the operation well. His immediate recovery from operation was excellent (Fig. 5), but six weeks later a low intermittent pyrexia commenced. An abscess appeared under the scalp and was controlled by aspiration and antibiotics. There remained a residual discharging sinus in the temporal fossa which did not finally heal until a small sequestrum was removed from the inner table at the centre of the bone flap one year after the original operation.

Pathology. Photographs of the specimen after operation gave a poor impression of the vascularity of the subarachnoid network (Fig. 6), but a radiograph showed the characteristic double curvilinear lines with great clarity (Fig. 7). The specimen was preserved in the Gordon Museum, Guy's Hospital, after two blocks had been taken for histological examination. Dr. A. L. Woolf subsequently reported on these blocks as follows:

'The pia arachnoid was extremely vascular, the vessels resembling arterioles and venules, but in both cases having an unusually thick collagenous coat (Fig. 8). This coat was rich in fibroblasts. The arterioles had a well-marked muscular media. Occasionally this muscular coat was very thick indeed. Deep to the pia was a thick feltwork of glial fibres. In the cortex itself loss of nerve cells was confined to perivascular clearings, but there was much gliosis. There was no increase in microglia. There were very numerous calcospherites throughout the cortex and white matter of the occipital lobe, but an origin in calcified blood vessels could not be definitely shown. The capillaries in the cortex were increased in prominence and some had unduly thickened walls. Calcospherites were less numerous in the frontal lobe.'

Progress. He has since been followed for over eight years, and has been completely free of fits and no anticonvulsant medication has been administered during that time. For the past three years he has been attending a school for physically handicapped children. He plays well with other children, and is not unduly aggressive or timid. Mentally, he is backward, but he is educable and interested in what goes on. He can read and write simple words and perform simple arithmetic, but his mental age is probably 7 years (Schonell R.; age 6 years 10 months, when actually 11 years old-D. Shalman). He has a right homonymous hemianopia. The right arm is held with the wrist flexed. He has good movements at the shoulder and a useful grip in the right hand which he uses to steady objects. The right leg is $2 \mathrm{~cm}$. shorter than the left, and although the leg is generally weak, he can walk with surprisingly little limp. The degree of hemiparesis has not been altered by operation. He was reported by his school teacher to be 'sociable and affectionate'.

Case 2. A.McK., 6 years of age, was referred by Dr. P. R. Evans. This girl was born with a port-wine stain of the left side of her face and scalp. She appeared otherwise normal until the age of 3 months when she began to have seizures involving the right side of her body. At first these were severe and frequent, lasting up to 10 minutes, and not responding noticeably to phenobarbitone. Generalized convulsions occurred at times. In her first two years of life she also had six separate attacks of pneumonia. Investigation elsewhere by left carotid arteriography was said to be normal, 


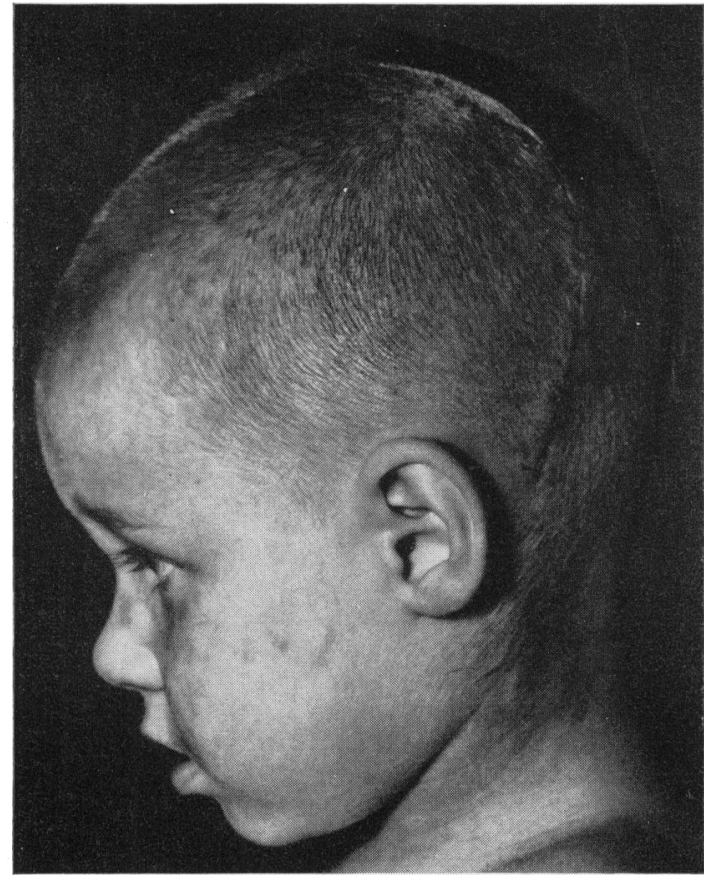

Fig. 5.-Case 1, appearances of wound 15 days after operation.

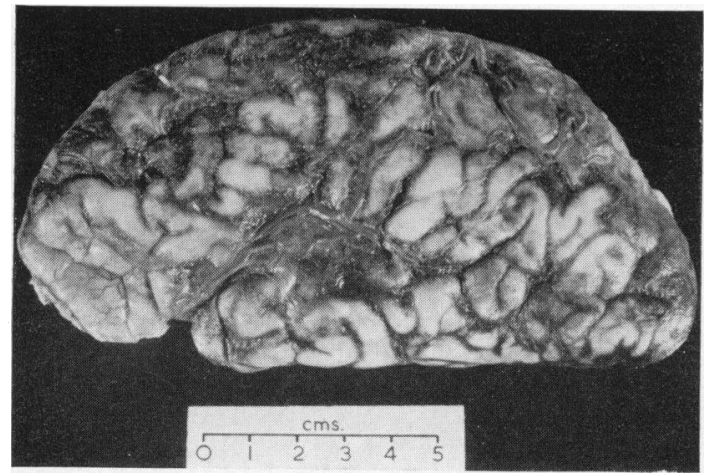

Fig. 6.-Case 1, lateral view of the resected hemisphere after excision to be contrasted with Fig. 4.

while pneumoencephalography showed gross atrophy of the left cerebral hemisphere. There was no mention of cerebral calcification. By the age of 18 months it was evident that her right limbs were weak and spastic, and by the age of 6 years her fits had become milder and would often only involve the right limbs without loss of consciousness. However, she would then average two to three attacks per week in spite of sedation with various

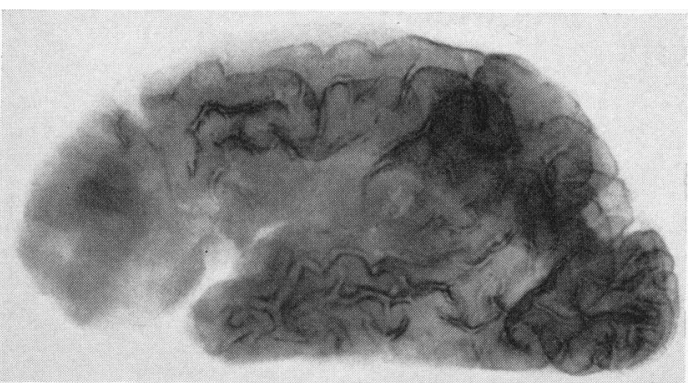

FIG. 7.-Case 1, radiograph of resected specimen after removal of two biocks for histological examination.

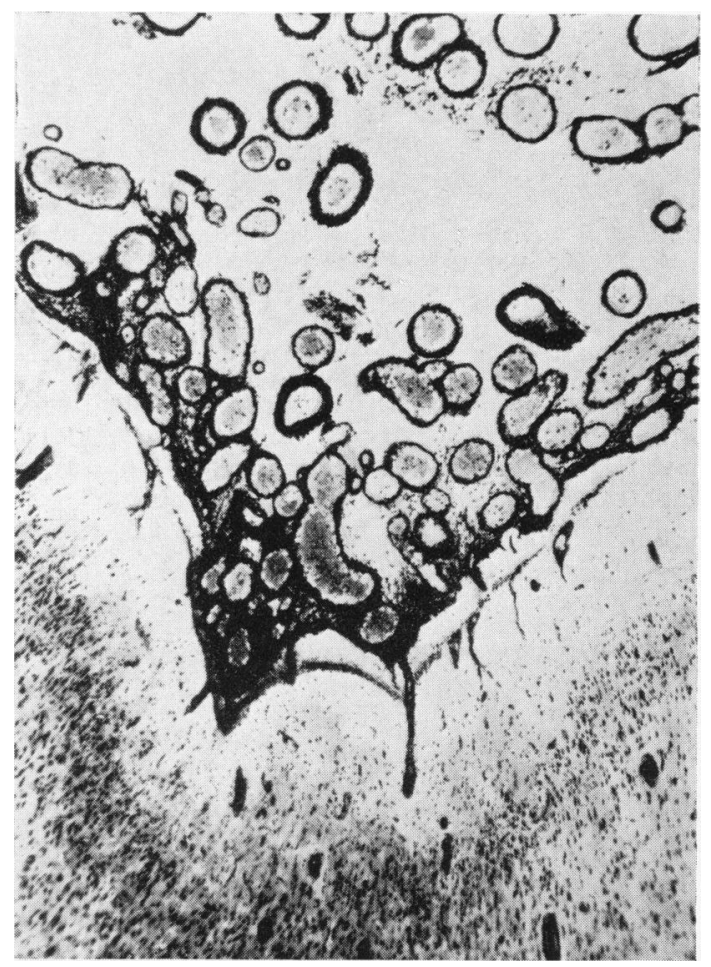

FIG. 8.-Case 1, photomicrograph showing numerous abnormal arterioles and venules in leptomeninges and also in outer layers of cortex. Cresyl violet $\times 41$.

anticonvulsant drugs. She did not talk until she was 2 years old, nor walk until she was 4 years. At 6 years she could say only a few simple words, and recognize and sing simple nursery tunes. Her behaviour had recently begun to deteriorate. She would fly into tempers if thwarted or disappointed, and in these tantrums she would scream, stamp and throw things around for periods of up to half an hour. 


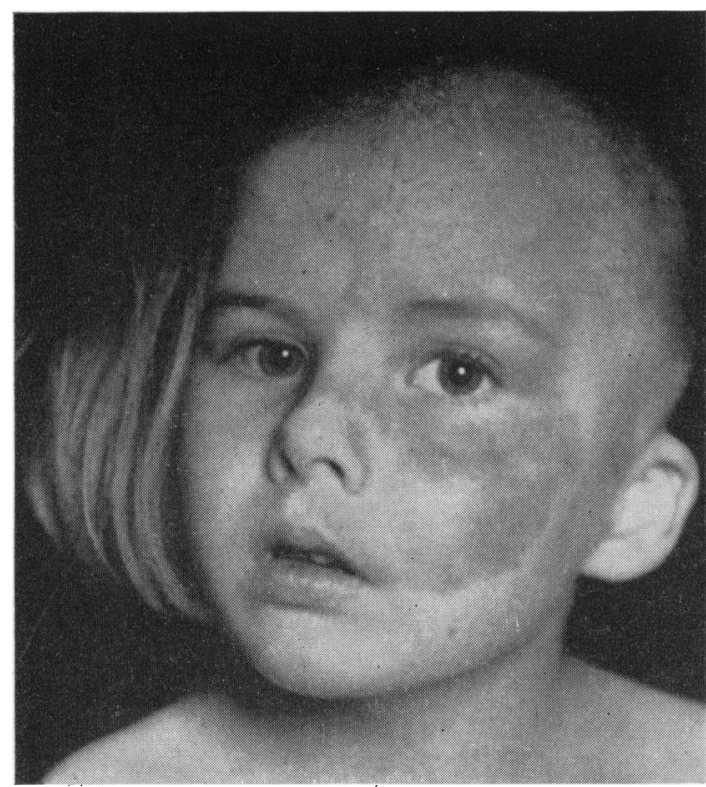

FIG. 9.-Case 2, photographed 15 days after operation to show extent of naevus as well as the scalp incision.

Examination. She was thin and undersized. The telang ectasis involved the left side of her face in the distribution of the upper two divisions of the trigeminal nerve (Fig. 9). She spoke in simple words and was not dysphasic. Her mental age was between 2 and 3 years (E. Norman). Her optic fundi were normal, but she showed a right homonymous hemianopia. There was an inconstant divergent strabismus. The right lower face was weak. The right arm was somewhat wasted and spastic, and about $3 \mathrm{~cm}$. shorter than the left. It was held flexed at the elbow, forearm hyperpronated, and with wrist and fingers flexed. Proximal movements were better preserved than distal, and she could abduct the shoulder against gravity, but her hand grip was feeble. The right leg was $4 \mathrm{~cm}$. shorter than the left with a spastic talipes equino-varus deformity. Muscle power was greatly diminished in all groups, but she could walk and even run unassisted although with a limp. She reacted equally to pinprick on both sides of the body.

INVESTIGATIONS. These were similar to those of Case 1. Radiographs of the skull showed that the left half of the cranial cavity was smaller than the right with extensive sinuous calcification of the left hemisphere (Fig. 10). On pneumoencephalography no air entered the ventricular system, but there was an extensive accumulation of subarachnoid air on the left side. Electroencephalography under seconal sedation showed absence of activity over the whole of the left hemisphere. No epileptic discharges were seen.

Operation. This was performed on April 1, 1952. The procedure and the appearances were similar to those observed in Case 1. Immediately on recovery from the anaesthetic, the condition of the right limbs was found to be unchanged. Her postoperative recovery was straightforward.

Pathology. The macroscopic and radiographic
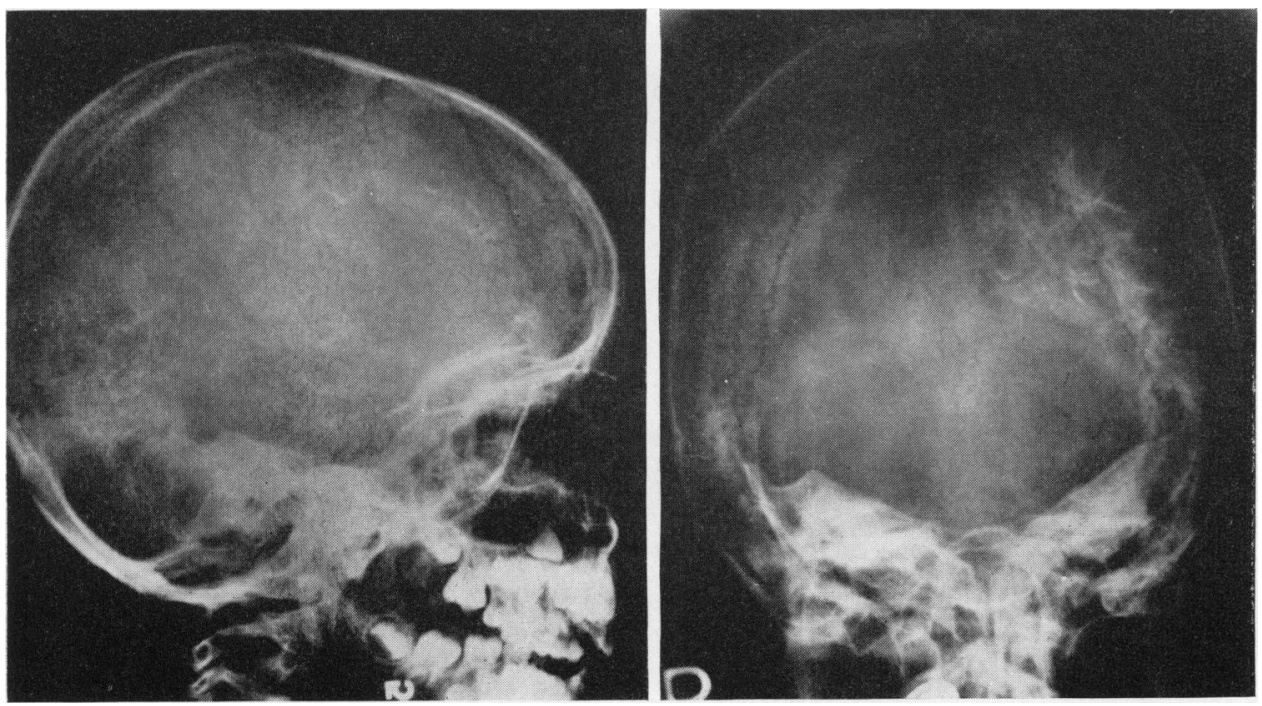

FIG. 10.-Case 2, straight radiographs showing characteristic calcification together with atrophy of left cerebral hemisphere. 
appearances of the specimen were similar to Case 1. Dr. Barbara Smith reported as follows:

'The pia-arachnoid was thickened and contained a collection of abnormal vessels (Fig. 11). In the

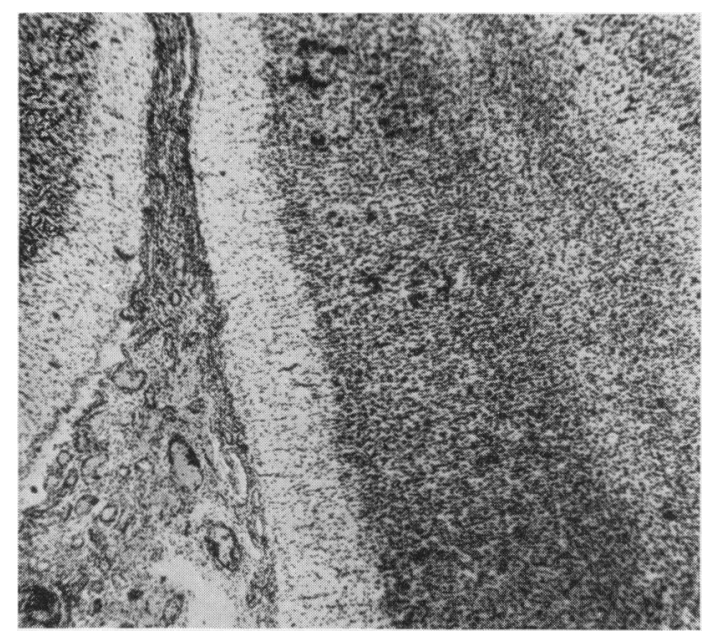

FIG. 11.-Case 2, photomicrograph showing thickened and abnormally vascular leptomeninges overlying an area of cortex which is gliotic and contains scattered calcospherites. Cresyl violet $\times 26$.

occipital block there was very marked subpial gliosis. This was less apparent in the frontal region. There were an increased number of astrocytes in the grey and white matter. Some of the pyramidal cells especially in the third layer appeared shrunken. Calcospherites were scattered throughout the cortex and white matter.'

Progress. She has since been observed for seven and a half years, and during that time has been completely free of seizures. Although rather excitable, she is good at home and has no behaviour disorder. She remains, however, very backward although educable. Her mental age at 7 years 4 months on the MerrillPalmer scale was 3 years 11 months, i.e. I.Q. 53 (E. Norman). At 13 years her mental ability as judged by reading primers, was 7 to 8 years. She attends a special school, and has participated in television performances. The hemiparesis and hemianopia are unchanged. She can appreciate light touch and pinprick equally on both sides, but two-point discrimination and postural sensibility is grossly impaired on the right side.

Case 3. S.W., $3 \frac{1}{2}$ years of age, was referred by Dr. P. R. Evans. This girl was born with a naevus of the right forehead. Starting at the age of 3 weeks, she had a series of fits in which she would become rigid and cyanosed for a few seconds. These its kept recurring two to six times daily for a period of three weeks, and have not since recurred. When she was 12 months old it was first noticed that she was liable to burst into screaming attacks. These attacks occurred whenever she craved attention, and once she received this she quietened down. In the tantrums she would frequently bang her head on the floor. At the age of 18 months her left limbs were first noticed to be weak, and subsequently the weakness gradually became more pronounced. She sat up at the age of 15 months, and walked at 2 years. Hemispherectomy was first considered when she was 18 months old, but as she was free of fits, it was decided to wait. However, her personality disorder and temper tantrums became so marked that she was almost unmanageable. She was, therefore, admitted at the age of $3 \frac{1}{2}$ years for operation.

Examination. She was a thin, irritable girl, who could, however, be pleasant when she was allowed to have her own way. There was a naevus of the right forehead in the distribution of the ophthalmic division of the trigeminal nerve (Fig. 12). The optic fundi were normal, but there was a left homonymous hemianopia. There was also a left infantile hemiplegia of marked degree. The left limbs were a little shorter and smaller than the right. The left arm was held across the chest with the fist clenched and the elbow flexed to a right

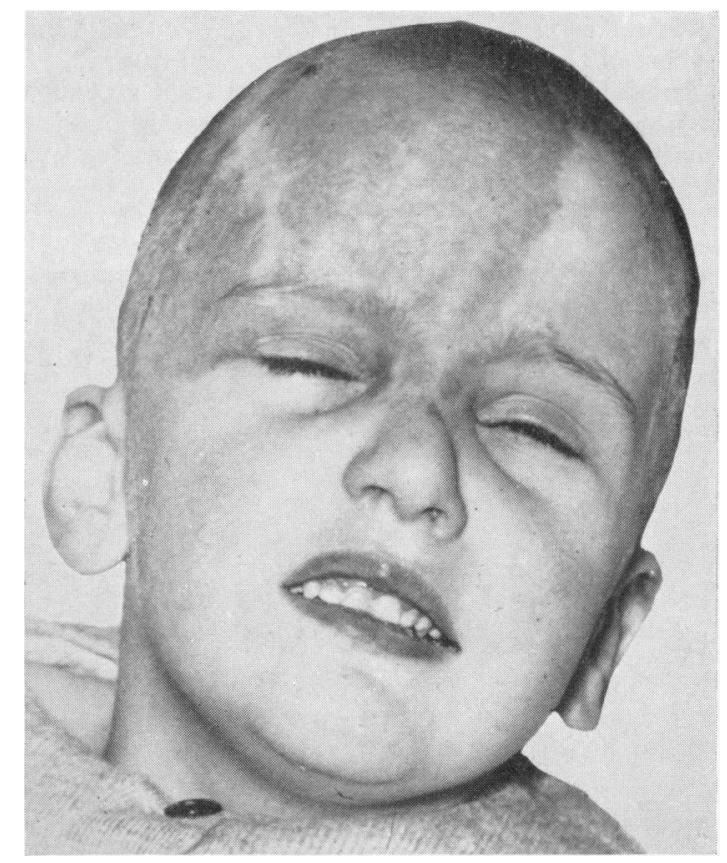

Fig. 12.-Case 3 before operation in a temper tantrum.

angle. She walked with a spastic left foot drop. Psychological testing showed that her mental age on the MerrillPalmer scale was 2 years and her intelligence quotient was 56 (Stanford Binet Form L.-Miss M. Newell).

INVESTIGATIONS. Skull radiographs showed the right half of the cranial cavity to be smaller than the left 

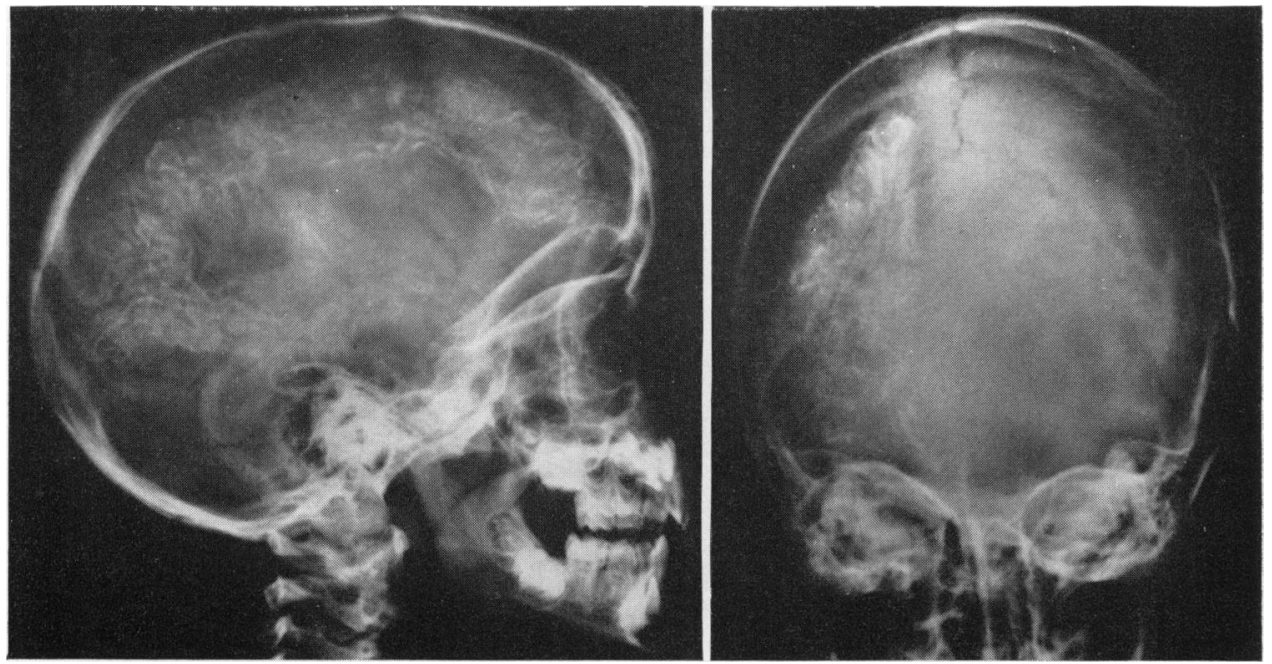

FIG. 13.-Case 3, radiographs showing characteristic calcification and right cerebral atrophy.

with extensive calcification in the right cerebral hemisphere of characteristic Sturge-Weber type (Fig. 13). A seconal E.E.G. record showed almost total absence of rhythmic activity over the right hemisphere with normal sleep rhythms on the left. There was no epileptic activity.

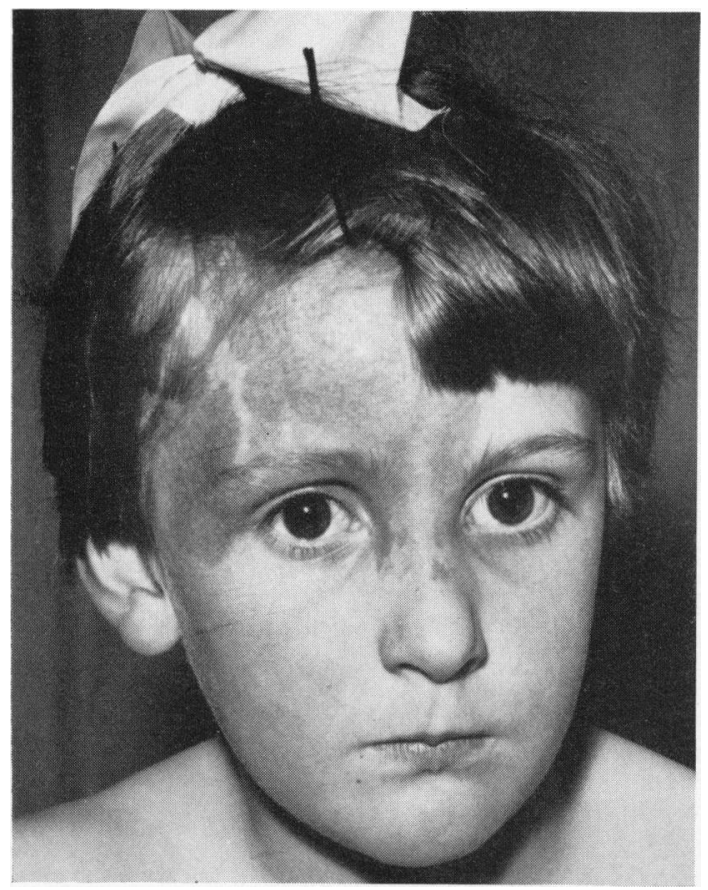

Fig. 14.-Case 3, 17 months after operation.
OPERATION. A right lateral craniotomy was performed on March 30,1954, with similar findings to the preceding cases. The whole right cerebral hemisphere presented a typical telangiectatic blush with a fine network of venous angiomatous vessels in the leptomeninges. The right hemisphere was removed in one piece except for its basal ganglia. The postoperative recovery was smooth.

Pathology. The macroscopic and radiographic appearances of the specimen were similar to those of the preceding two cases, but unfortunately the specimen was subsequently mislaid and no pathological studies were made.

Progress. Since then her progress has been reasonably good, although she has functioned at a defective level. She has had no fits and no temper tantrums and her parents describe her behaviour as satisfactory. At the age of 5 years (Fig. 14) the Stanford-Binet Form L. gave her mental age as $3 \frac{1}{2}$ years and her I.Q. as 63 . Since then she has made reasonable progress at school, and now, at the age of $8 \frac{1}{2}$ years, can just read and write. Her left upper limb has remained very weak and is held flexed across her chest as before without any useful grip in the left hand. The left leg showed very little weakness, and the gait was only slightly abnormal. A number of tenotomy operations have been performed to correct a talipes equinus. Her present full scale intelligence quotient on the W.I.S.C. scale is 75 (D. Shalman), and she is attending a school for educationally subnormal children (Dr. A. C. Blandy).

Case 4. G.L., 16 years of age, was referred by Dr. N. Acheson. This youth, the eldest patient in our series, was born with a naevus covering most of the left face, 
patchily over much of his body on the left side and to a slighter extent on the right side. A right hemiparesis was noted in early infancy. From the age of 4 months onwards he exhibited frequent epileptic attacks in which he rubbed his hands together, had slight twitches of his limbs, and was out of contact for one to two minutes. From the age of 14 years he had major convulsions lasting three to five minutes and recurring every four to six weeks in spite of medication. He had always been mentally defective and aggressive, and in recent years had exhibited frequent temper tantrums. His parents assessed his mental age as 4 to 5 years, and treated him as such. He wet his bed most nights.

Examination. He was small (5 ft. 2 in.) and underdeveloped. The naevus was extensive not only over the left face (Fig. 15), but over much of his body as well (Fig. 16). The left retina was a deeper red than the right and the left eyeball was bigger than the right. However, he appeared to see equally well with each eye, although a right homonymous hemianopia was present. A typical right-sided infantile hemiplegia was present with shortened spastic right limbs. His speech was limited to simple sentences, but he could neither count beyond 10 nor tell the time on a watch. He named common objects correctly. He stood in a stooped position and limped when he walked. His secondary sexual development seemed normal. An attempt was made to assess his intelligence quotient, but he proved untestable (Dr. V. Meyer).

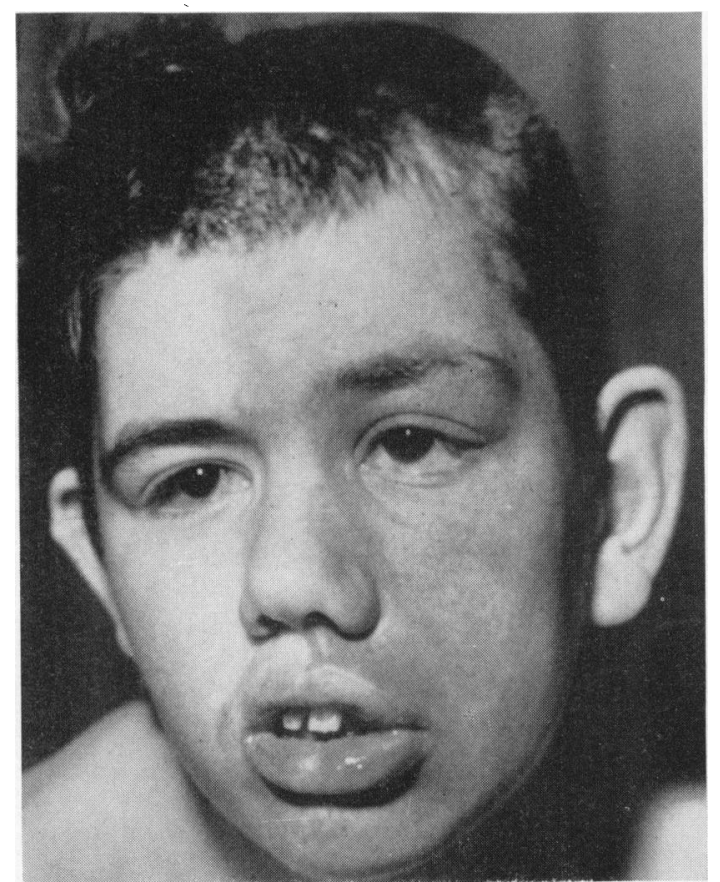

FIG. 15.-Case 4, showing left facial naevus and left buphthalmos.

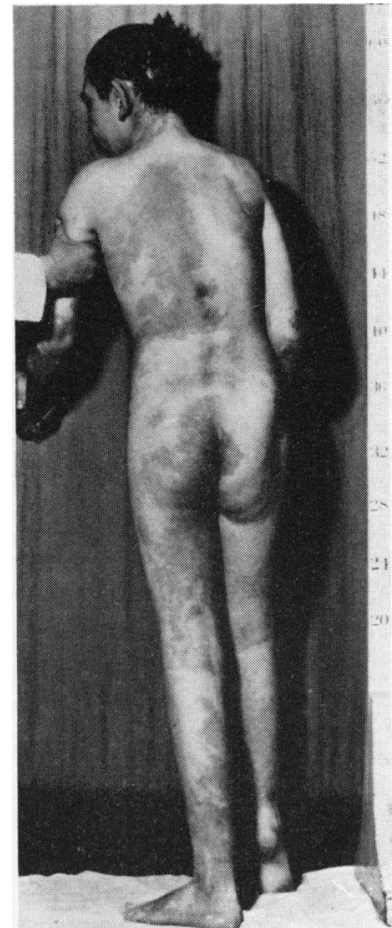

Fig. 16.-Case 4, showing patchy naevus over trunk.

INVESTIGATIONS. Skull radiographs showed a clear hemicranial atrophy with several large irregular blobs of calcification scattered throughout the left cerebral hemisphere (Fig. 17). Only in the occipital region could the double curvilinear lines which are more characteristic of Sturge-Weber disease be discerned. Pneumoencephalography disclosed a normal-sized ventricular system with, as in Case 1, considerable pooling of air in the subarachnoid spaces over the left cerebral cortex. The electroencephalogram showed almost complete absence of activity over the left hemisphere with normal alpha activity on the right side. No epileptic activity was seen in the routine records, but in a special study employing sphenoidal electrodes and thiopentone narcosis (Pampiglione and Kerridge, 1955) an active focus of spike discharges, both surface-negative and surface-positive was seen at the right sphenoidal area. We presumed, on clinical grounds, that this focus was being paced from the left side.

OPERATION. A left-sided craniotomy, performed on March 9, 1956, revealed an extensive angiomatous malformation of the Sylvian veins extending $6 \mathrm{~cm}$. by $3 \mathrm{~cm}$. (Fig. 18). The subarachnoid spaces over the rest of the hemisphere were covered with a close network of finer veins. Electrocorticography revealed a surprising amount of irregular slow-wave activity in the diseased hemisphere. The entire hemisphere except for its basal ganglia was then removed in one piece without much difficulty. 

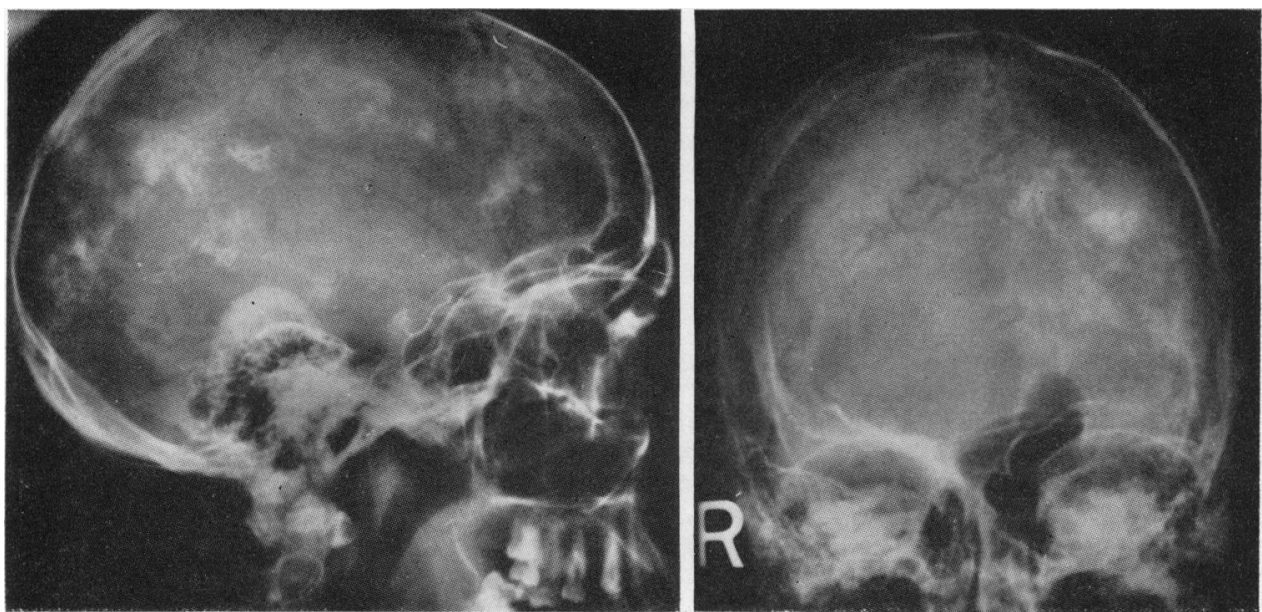

FIG. 17.-Case 4, radiographs showing peculiar type of cerebral calcification.

Pathology. Dr. Barbara Smith reported that two blocks of cortex showed 'a mass of dilated abnormal vessels embedded in connective tissue. In the outer layers of the cortex and in the white matter there were large masses of calcium, particularly in relation to the depths of the sulci. There was some gliosis of the cortex'. A diffuse angioma was present in the subarachnoid space (Fig. 19). A portion of the scalp with the naevus showed that the "dermal papillae were more vascular than normal'. In the choroid plexus 'there was only a small area of normal choroid plexus. The rest consisted of an angioma with a number of calcified nodules'. A piece of the cranial vault showed 'no abnormality'.

Progress. He made a good recovery from operation but there was no change in his neurological signs. His behaviour, however, was very much improved, and a month after operation it proved possible to assess his intelligence on the Wechsler-Bellvue scale (I.Q. 30).

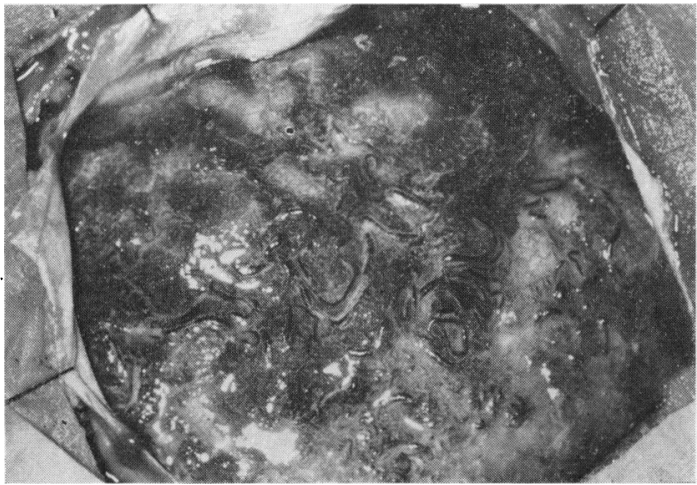

FIG. 18.-Case 4, operative appearances of left cerebral hemisphere as viewed from the head end of the operating table.
Three years later his parents reported that he had had no fits since operation, and was 'more even-tempered ard manageable'.

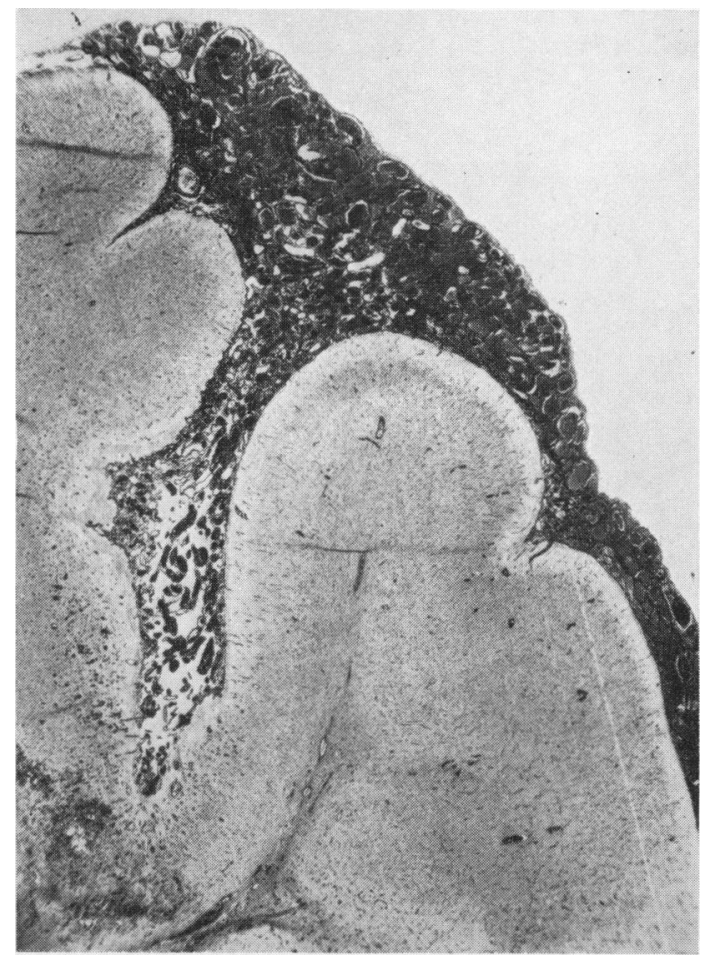

FIG. 19.-Case 4, photomicrograph showing a diffuse leptomeningeal angioma, extending into a sulcus. The cortex in the floor of the latter shows scattered masses of calcium. Haematoxylin and van Gieson $\times 7$. 
Case 5. R.W., 12 years of age, was referred by Dr. I. MacKenzie. This boy was born with a naevus in the left forehead. At the age of $4 \frac{1}{2}$ months his mother noticed that he appeared disinclined to use the right hand. His progress between the ages of $4 \frac{1}{2}$ months and 2 years was slower than normal, and he did not walk until he was 2 years of age. At the age of 9 months he began to have convulsive seizures involving the right side of the body with loss of consciousness. These continued ranging in frequency from as many as 20 a day to as few as two or three a week. He started at an ordinary school when 5 years old, but at the age of 7 years was sent to a special school. There he did quite well and by the age of 8 years he could hold a conversation. At the age of 12 years he had only recently learnt to read and write, and to do simple arithmetic. There was no behavioural problem.

EXAMINATION. The typical telangiectasis involved the area of the ophthalmic division of the left trigeminal nerve, and the right side of the face was a little smaller than the left. His speech was normal. The optic fundi were normal, but a right homonymous hemianopia was present. There was a slight right lower facial weakness. The right limbs were slightly shorter than the left, and were also somewhat weak and spastic, but he could grip with his hand and had some individual finger movements. There was only slight weakness of the right leg, the muscle power being about $80 \%$ of normal. The tendon jerks were equal on the two sides, but the right plantar response was feebly extensor. Light touch and pain sensibility were normal on each side, but he had astereognosis in his right hand and two-point discrimination was unreliable. He walked well, but he was noticed to plant the right foot on the ground more firmly than the left. His intelligence rating on the WechslerBellvue full scale was 57 (A. R. Dabbs).

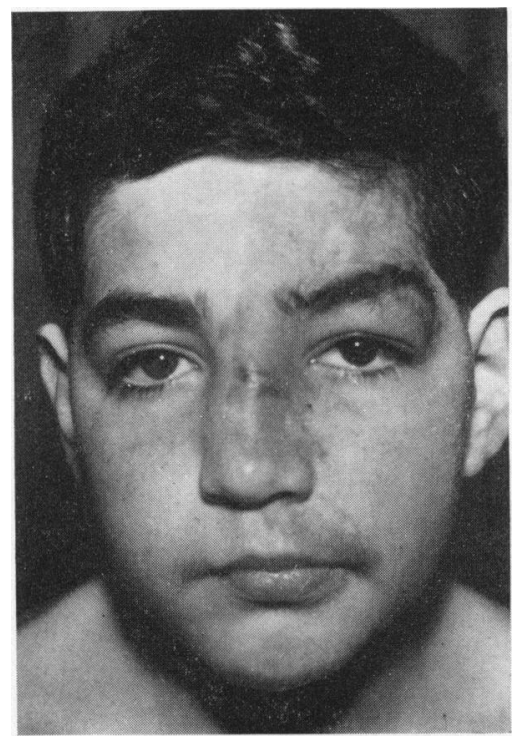

Fig. 20.-Case 5, showing naevus.
INVESTIGATION. Skull radiographs showed that the left hemicranium was much smaller than the right, but the calcification indicative of Sturge-Weber disease was only present in a small area at the left occipital pole (Fig. 21). Pneumoencephalography, however, showed

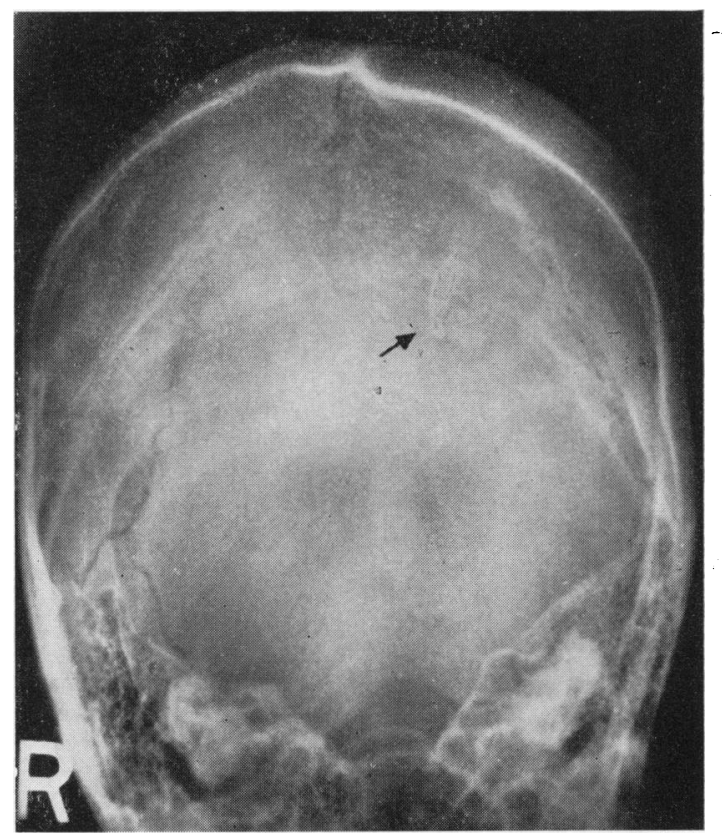

FIG. 21.-Case 5, radiographs (Towne's projection) showing characteristic calcification present at only a small area at left occipital pole (arrow).

that although the ventricular system was of normal size, the left cerebral hemisphere was shrunken with considerable pooling of air in its subarachnoid spaces (Fig. 22). Electroencephalography showed a 'gross reduction of both normal and barbiturate fast rhythm throughout the whole left hemisphere. A large amount of bilateral subcortical activity was seen better in the right side than the left. A few independent spikes were seen in the left frontal areas and occasionally on the right' (D. Hill).

Operation. A left-sided hemispherectomy was performed on July 17, 1956. The whole surface of the left cerebral hemisphere was seen to be covered by an angiomatous malformation similar to our previous cases. Electrocorticography revealed poor activity over the posterior two-thirds of the hemisphere with relatively normal activity in the frontal region, where occasional spike discharges were seen (G. Pampiglione).

Pathology. Although the surface of the cerebral hemisphere presented an evenly distributed flushed appearance of the cortex and leptomenginges (Fig. 23), radiographs of the specimen disclosed calcification only 


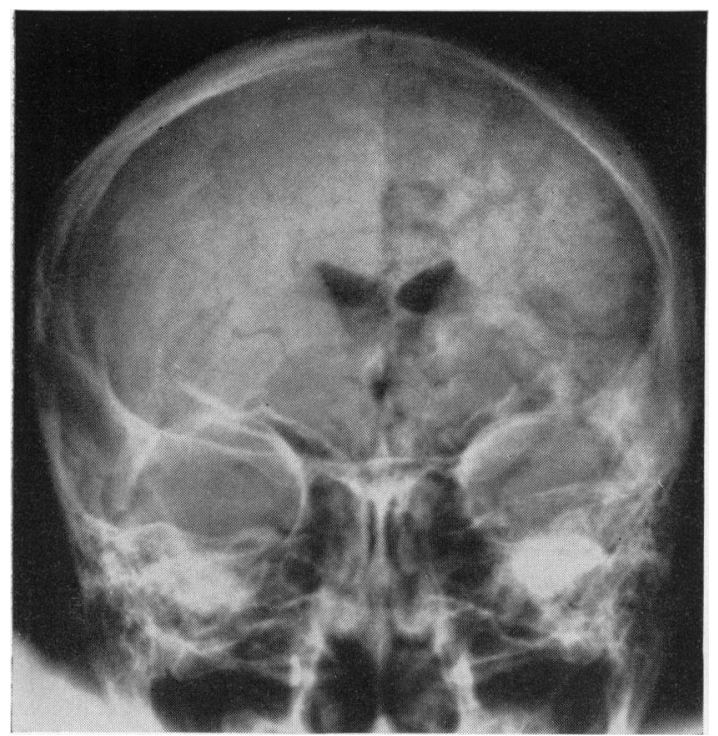

Fig. 22.-Case 5, antero-posterior air encephalogram showing shrunken left cerebral hemisphere with capacious subarachnoid spaces.

at the occipital pole (Fig. 24). Dr. Barbara Smith . reported on a block from the parietal lobe as follows:

'The thickened pia-arachnoid was full of large vascular spaces with thin collagenous walls. These spaces did not involve the nervous tissue itself. There were an increased number of astrocytes in the cortex, particularly in the superficial layers, and considerable submarginal gliosis. Some of the neurones showed ferruginous incrustation. There was only a small amount of calcium in the cortex.'

Progress. The postoperative course has been smooth, and he has not subsequently had any further fits during the three year follow-up period. At first,

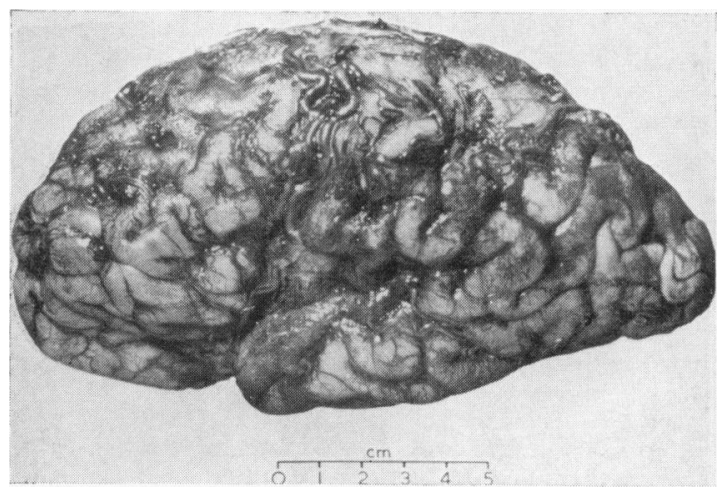

Fig. 23.-Case 5, view of resected hemisphere showing diffuse vascularity of the pia-arachnoid. however, his right hemiparesis was markedly increased, and during the first two weeks there was very little voluntary movement in either the right arm or the right leg. Also there was some questionable dysphasia, while sensibility to touch and pinprick was impaired on the right side. Thereafter, however, there was a gradual improvement in power and sensation, so that six weeks after operation, when he was discharged, he could walk again. At that time he had some voluntary movement of the shoulder and elbow, but none of the wrist and fingers. Power at the right hip and knee was approximately $30 \%$ of normal, but there was a foot drop. Sensibility had returned to its preoperative level. Psychological testing now gave an I.Q. of 70 on the Wechsler scale, but it was thought that this apparent improvement was not statistically significant and

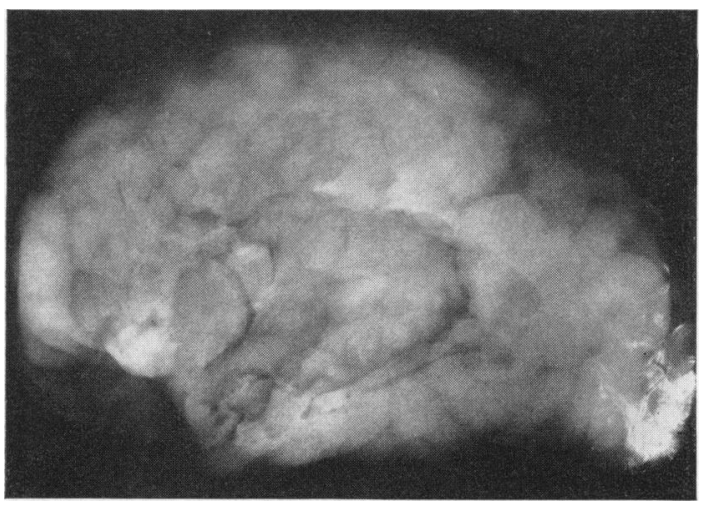

F IG. 24.-Case 5, radiograph of specimen showing characteristic calcification only at occipital pole.

might be the result of practice. The E.E.G. was flat on the left, and showed normal alpha rhythm on the right side. A short burst of wave and spike activity was seen on over-breathing (D. Hill). The most recent intelligence quotient on the W.I.S.C. scale is 66 (D. Shalman). The patient had commenced work as a messenger boy.

\section{Discussion}

These five cases are all well marked examples of Sturge-Weber disease, the essential abnormality of which is the congenital lepto-meningeal venous angioma. Our cases conform to the excellent recent descriptions of pathological data given by Medoc et al. (1953-54), by Lichtenstein (1954), by Wohlwill and Yakovlev (1957), and by Norman (1958). The angioma brings about a progressive destruction of the cerebral cortex, and the clinical effects depend upon the location of the damage and the rapidity with which it occurs. It does not lead to an intracranial bruit.

The case histories of our patients are typical of the more advanced cases of this condition and the 
TABLE

SUMMARY OF RESULTS OF OPERATION

\begin{tabular}{|c|c|c|c|c|c|c|c|c|c|}
\hline \multirow[b]{2}{*}{ Case No. } & \multicolumn{5}{|c|}{ Clinical Features at Time of Operation } & \multicolumn{4}{|c|}{ Clinical Features at Time of Follow-up } \\
\hline & $\begin{array}{l}\text { Age } \\
\text { (yrs) }\end{array}$ & $\operatorname{Sex}$ & $\begin{array}{l}\text { Laterality of } \\
\text { Affected } \\
\text { Hemisphere }\end{array}$ & Epilepsy & Behaviour & $\begin{array}{c}\text { Duration of } \\
\text { Follow-up } \\
\text { (yrs) }\end{array}$ & Epilepsy & Behaviour & Intelligence \\
\hline 1 & $3 \frac{1}{2}$ & $\mathbf{M}$ & Left & $\begin{array}{l}\text { Several attacks } \\
\text { daily }\end{array}$ & Sullen & 8 & Fit-free & Sociable & $\begin{array}{l}\text { Improved, } \\
\text { educable }\end{array}$ \\
\hline 2 & 6 & $\mathbf{F}$ & Left & $\begin{array}{l}\text { Two to three } \\
\text { attacks per week }\end{array}$ & $\begin{array}{l}\text { Frequent temper } \\
\text { tantrums }\end{array}$ & $7 \frac{1}{2}$ & Fit-free & Sociable & $\begin{array}{r}\text { Improved, } \\
\text { educable }\end{array}$ \\
\hline 3 & $3 \frac{1}{2}$ & $\mathbf{F}$ & Right & $\begin{array}{l}\text { Fits had ceased } \\
\text { during infancy }\end{array}$ & $\begin{array}{l}\text { Frequent temper } \\
\text { tantrums }\end{array}$ & 5 & Fit-free & Sociable & $\begin{array}{l}\text { Improved, } \\
\text { educable }\end{array}$ \\
\hline 4 & 16 & $\mathbf{M}$ & Left & Fits every month & $\begin{array}{l}\text { Frequent temper } \\
\text { tantrums }\end{array}$ & 3 & Fit-free & Satisfactory & $\begin{array}{r}\text { Still grossly } \\
\text { defective }\end{array}$ \\
\hline 5 & 12 & $\mathbf{M}$ & Left & $\begin{array}{c}\text { Several attacks } \\
\text { daily }\end{array}$ & Normal & 3 & Fit-free & Still normal & $\begin{array}{r}\text { Improved, } \\
\text { educable }\end{array}$ \\
\hline
\end{tabular}

salient features are summarized in the Table. At birth the infant appears quite normal apart from the unilateral facial telangiectasis. After a varying period, in our cases from 3 weeks to 9 months, the child begins to have epileptic seizures which initially involve the side of the body contralateral to the naevus. Later they may spread to the other side as well. The frequency and severity of the fits vary widely. At about the same time as the fits commence, the limbs in the side opposite to the naevus are noted to be weak. This weakness apparently increases as the child grows, and may develop into a marked infantile hemiplegia with wasted shortened and spastic limbs. Further, as the child grows older, mental backwardness becomes evident, and temper tantrums and other behaviour disorders may make their appearance. The characteristic calcification seen in radiographs may be absent in early infancy, and not appear until later. The combination of epilepsy, backwardness and unmanageability may make institutional care necessary. All five of our cases had both facial naevus and infantile hemiplegia. Cases 1,2 and 4 exhibited the most complete clinical pictures: Case 3 had only a transient epilepsy, but a persistent personality disorder, and Case 5 had epilepsy but a normal personality.

Our cases also illustrate well the value of radiology in this condition, a topic which has recently been intensively reported by Poser and Taveras (1957). All five cases showed marked hemicranial atrophy with a shrunken cerebral hemisphere, which was well outlined in four of the cases by the characteristic calcification and in all five cases by pneumoencephalography. In two cases (Case 1 and 2) calcification was not noted in the skull radiographs taken in infancy, but was markedly developed by the third year of life. Poser and Taveras (1957) also remark on this. In Case 5 the calcification was detectable only in the occipital pole even although the angioma was widespread. Carotid angiography was performed in only two of our cases, both during infancy, and no vascular abnormality was noted. Such a negative finding (except for evidence of hemicranial atrophy) agrees with the usual consensus of opinion (Moniz and Lima, 1935; Bergstrand, Olivecrona and Tönnis, 1936; Riechert, 1943). However, Poser and Taveras (1957) point out that in many cases the presence of the capillaryvenous angioma can be disclosed by serial angiography, and that other lesions such as arterial thromboses and external carotid artery anomalies may be disclosed. Only one case with a cirsoid arteriovenous malformation appears to have been reported. None of our cases had suffered from intracranial haemorrhage, although instances both of subarachnoid haemorrhage and of subdural haemorrhage have been reported in this condition (Cushing, 1906; Poser and Taveras, 1957).

There are still comparatively few case reports in the literature of operative intervention for SturgeWeber disease. Balado (Dimitri and Balado, 1933) performed a craniotomy under local anaesthesia in 1930 on Dr. Dimitri's patient, then aged about 20 years, exposing a cirsoid venous angioma which he treated by electrocoagulation of the principal surface vessels without any alteration in consciousness. Subsequently the patient continued to have attacks, but with a reduced frequency. Krayenbühl et al. (1957) state that Tönnis, in 1934, tried the same procedure, but did not describe the results.

A few neurosurgeons report cases in which the Sturge-Weber malformations appear to have been localized to a small part of the cerebral hemisphere 
which was then excised, apparently with benefit. Thus Broager and Hertz (1949) report the case of a 5-year-old boy in which the left premotor region was excised largely on E.E.G. evidence. There was a naevus of the face and a naevus on the inner side of the dura in the premotor region, while a number of fine tortuous vessels were noted in the pia of the affected region. The patient was followed up for one year, and was free of fits, but still on anticonvulsive medication. Other surgeons who have reported comparable cases include Green, Foster and Berens (1950), occipital lobe with characteristic calcification; Huber and Zweymüller (1954), parietal lobe; and Krayenbühl et al. (1957), temporal lobe. However, a recurrence of epilepsy can follow upon these limited excisions (Krayenbühl, 1959).

Cairns and Davidson (1951) record the first case successfully treated by hemispherectomy. This was a 7-year-old girl with infantile hemiplegia, fits and behavioural disturbances. One year later she was free of fits, her intelligence quotient had risen from 63 to 73 , and she appeared educable. Polani (1952) in the following year, gave a preliminary report on the first two cases included in this present paper. Obrador Alcalde (1958), in a recent paper, mentions that other cases have been successfully operated on by Paillas and by McKissock (Laine and Gros, 1956), by French et al. (1955), and by Goodall (1957), and he adds a sixth case report from his own experience. This was an 11-year-old patient observed to be free from fits 14 months after the operation.

A recent report from the Mayo Clinic (Peterman et al., 1958) mentions that operation was carried out in four of 35 cases seen in the period from 1935 to 1956. Three of these cases had been submitted to a lobectomy rather than to a hemispherectomy with relief of seizures in one case. The fourth patient had undergone a craniotomy, but the lesion was not extirpated because of the extent of the angioma. Of the 35 cases, 31 had had adequate follow-up studies, and these showed the variability which is encountered in the course of this disease; 17 of the patients were considered well, and two had never had a convulsion; 15 had continued to have seizures, some, however, infrequently. One other of their patients had undergone a cortical excision elsewhere with a successful result. Four patients had died, one after craniotomy and three after progressive deterioration at ages between 9 months and $7 \frac{1}{2}$ years. Ten patients had done poorly, five being confined to institutions. Of the 17 patients who had done well, only three showed mental retardation. One indeed had graduated from college, and several were married and rearing families.

The drastic procedure of cerebral hemispherectomy or the less severe one of lobectomy are therefore justified only when there is a proper indication, i.e. disabling epilepsy and/or a personality disorder. If the angiomatous lesion is circumscribed in the brain, a local extirpation may be all that is necessary (Broager and Hertz, 1949), but, if it is widespread throughout one cerebral hemisphere, removal of that hemisphere is indicated.

Our cases show that provided the other hemisphere is structurally normal, hemispherectomy may be confidently expected to abolish the seizures and produce a real improvement in the personality. The infantile hemiplegia is not improved, and subsequent operative procedures may prove necessary to correct a talipes equinus. The patient remains backward, but his intelligence as rated by the usual tests may improve a little even in relation to his increased age, and he may function as a high-grade mental defective and be educable. Thus it has led to improvement in learning in all four of our patients who were operated upon during childhood. It did not benefit Case 4 who was operated upon as an adult. Our experience in all these respects is in agreement with the results of hemispherectomy performed for other types of infantile hemiplegia (Krynauw, 1950).

Before the operation is undertaken, the condition of the other hemisphere is checked by pneumoencephalography and electroencephalography. Pooling of air over the surface in dilated subarachnoid spaces or ventricular dilatation on the supposedly good side indicates damage to it. The electroencephalographic findings need to be interpreted with caution. Krynauw (1950) demonstrated in his cases of infantile hemiplegia that E.E.G. abnormalities in the good hemisphere often cleared up after removal of the diseased one. This may explain both the postoperative improvement in personality and in intelligence.

Given proper indications, the operation is well worthwhile, and the question arises as to the best stage at which it should be performed. An opinion in this respect is largely based on theoretical premises. We have no evidence to suppose that it will benefit a child with infantile hemiplegia but without epilepsy or a personality disorder. If, however, one or both of these is present (and in our cases they had all appeared within the first year of life), the child should be operated on at an early stage in order to stop the seizures and improve learning capacity. The skull of a young infant, however, because of its flexibility, makes the closure 
of a large craniotomy difficult. The youngest age at which operation was performed in this series was $3 \frac{1}{2}$ years, and no great difficulty was encountered. On theoretical grounds the child could have been operated on with equal ease between the ages of 2 and 3 years, which is probably the preferable age period. As in other conditions causing infantile hemiplegia, aphasia does not appear, even when the left cerebral hemisphere is removed (Krynauw, 1950).

\section{Summary}

The case histories of five patients with advanced Sturge-Weber disease (encephalotrigeminal angiomatosis) are recorded. All exhibited epilepsy and/or a behavioural disturbance occurring in association with an infantile hemiplegia and their epilepsy and personality conditions were improved by excision of the affected cerebral hemisphere (hemispherectomy), but not their infantile hemiplegia. All remained mentally backward, but the four who were operated on during childhood proved to be educable. These findings conform to the observations made by others who have performed hemispherectomy for this condition.

We wish to thank the various physicians who have referred us their cases. In particular we are grateful to Dr. P. R. Evans, Mr. P. H. Schurr, Professor P. M. Daniel, Dr. A. L. Woolf, and Dr. Barbara Smith who have helped us with the text, and the various psychologists who have given us their reports. The radiographs were provided by Dr. R. D. Hoare. We are also grateful to the Medical Research Council for a grant towards the investigation of patients with epilepsy treated by surgery which has made the follow-up possible.

\section{REFERENCES}

Bergstrand, H. Olivecrona, H. and Tönnis, W. (1936) Gefässmissbildungen und Gefässgeschwülste des Gehirns. Thieme, Leipzig.

Broager, B. and Hertz, H. (1949). An electroencephalographically localized focus in a case of Sturge-Weber syndrome, extirpated with good result. Acta psvchiat. $(K b h), 24,1$.

Cabieses, F., Jerí, R. and Landa, R. (1957). Fatal brain-stem shift after hemispherectomy. J. Neurosurg, 14, 74 .

Cairns, H. and Davidson, M. A. (1951). Hemispherectomy in the treatment of infantile hemiplegia. Lancet, 2, 411.

Cushing, H. (1906). Cases of spontaneous intracranial hemorrhage associated with trigeminal nevi. J. Amer. med. Ass., 47, 178

Dandy, W. E. (1928). Removal of right cerebral hemisphere for certain tumors with hemiplegia. Ibid., 90, 823

Dimitri, V. (1923). Tumor cerebral congénito (angioma cavernoso) Rev. Asoc. méd. argent., 36, 1029.

and Balado, M. (1933). Angioma cerebral operado. Ibid 47, 3045.

French, L. A., Johnson, D. R., Brown, I. A. and Van Bergen, F. B (1955). Cerebral hemispherectomy for control of intractable convulsive seizures. J. Neurosurg., 12, 154.

Geyelin, H. R. and Penfield, W. (1929). Cerebral calcification epilepsy; Endarteritis calcificans cerebri. Arch. Neurol. Psychiat. (Chicago), 21, 1020.

Goodall, R. J. (1957). Cerebral hemispherectomy: Present status and clinical indications. Neurology (Minneap.), 7, 151.

Green, J. R., Foster, J. and Berens, D. L. (1950). Encephalotrigeminal angiomatosis (Sturge-Weber syndrome); with particula reference to the roentgenological aspects before and after neurosurgery. Amer. J. Roentgenol., 64, 391.

Gros, C. (1951). Technique de l'hémisphérectomie. Rev. neurol., 85,484

and Vlahovitch, B. (1954). L'hémisphérectomie Cérébrale. Causse, Graille and Castelnau, Montpellier

Hebold, O. (1913). Haemangiom der weichen Hirnhaut bei Naevus vasculosus des Gesichts. Arch. Psychiat. Nervenkr., 51, 445.

Huber, K. and Zweymüller, E. (1954). Monosymptomatische Form des Krankheitsbildes von Sturge-Weber. Wien. Z. Nervenheilk., 9, 459 .

Kalischer, S. (1897). Demonstration des Gehirns eines Kindes mit Teleangiectasie der linksseitigen Gesichts-Kopf haut und Hirnoberfläche. Berl. klin. Wschr., 34, 1059.

(1901). Ein Fall von Teleangiectasie (Angiom) des Gesichts und der weichen Hirnhaut. Arch. Psychiat. Nervenkr., 34, 171.

Krabbe, K. H. (1934). Facial and meningeal angiomatosis associated with calcifications of the brain cortex: Clinical and anatomopathologic contribution. Arch. Neurol. Psychiat. anatomopathologic
(Chicago), 32, 737.

Krayenbühl, H. (1959). Personal communication.

, Yasargil, G., and Uehlinger, E. (1957). Klinischer und pathologisch-anatomischer Beitrag zur Sturge-Weber-Krabbe' schen Krankheit. Dermatologica (Basel), 115, 555

Krynauw, R. A. (1950). Infantile hemiplegia treated by removing one cerebral hemisphere. J. Neurol. Neurosurg. Psychiat., 13, 243.

Laine, E. and Gros, C. (1956). L'hémisphérectomie. Masson, Paris.

Lichtenstein, B. W. (1954). Sturge-Weber-Dimitri syndrome: Cephalic form of neurocutaneous hemangiomatosis. A.M.A. Arch. Neurol. Psychiat., 71, 291.

McKissock, W. (1953). Infantile hemiplegia. Proc. roy. Soc. Med., 46, 431 .

- (1954). The operative technique for cerebral hemispherectomy in the treatment of infantile hemiplegia. Z Zl. Neurochir. 14, 42 .

Medoc, J., Sotelo, J. R., Arana Iñiquez, R. and Estable Puig, F. (1953-54). Contributión a la histopathologica y patogenia de la enfermedad de Sturge-Weber-Dimitri. An. Inst. Neurol. (Montevideo), 10, 65 .

Moniz, E. and Lima, A. (1935). Pseudo-angiomes calcifiés de cerveau: Angiome de la face et calcifications corticales du cerveau (maladie de Knud H. Krabbe). Rev. neurol., 63, 743.

Norman, R. M. (1958). Encephalofacial angiomatosis, in Neuropathology, ed. J. G. Greenfield, p. 349 . Arnold, London.

Obrador Alcalde, S. (1950). Extirpacion del hemisferio cerebral derecho por hemiatrofia cortical. Rev, clin. esp., 36, 172.

(1952). About the surgical technique for hemispherectomy in cases of cerebral hemiatrophy. Acta Neurochir. (Wien), $3,57$.

(1958). Hemisferectomia cerebral en el tratamiento de la epilepsia secundaria a la angiomatosis de Sturge-Weber-Dimitro. Acta neurol. lat.-amer.. 4, 70

Pampiglione, G. and Kerridge, J. (1955). E.E.G. abnormalities from the temporal lobe studied with sphenoidal electrodes. J. Neurol. Neurosurg. Psychiat., 19, 117.

Peterman A. F. Hayles, A. B., Dockerty, M. B. and Love, J. G. (1958). Encephalotrigeminal angiomatosis (Sturge-Weber disease). J. Amer. med. Ass., 167, 2169

Polani, P. E. (1952). Encephalo-trigeminal angiomatosis (SturgeWeber syndrome) treated by removal of the affected cerebral hemisphere. Proc. roy. Soc. Med., 45, 860

Poser, C. M. and Taveras, J. M. (1957). Cerebral angiography in encephalo-trigeminal angiomatosis. Radiology, 68, 327.

Riechert, T. (1943). Die Arteriographie der Hirngefässe. Urban and Schwarzenberg. Berlin.

Schirmer, R. (1860). Ein Fall von Teleangiektasie. Albrecht v. Graefes Arch. Ophthal., 7, 119

Sturge, W. A. (1879). A case of partial epilepsy, apparently due to a lesion of one of the vaso-motor centres of the brain. Trans. clin. Soc. Lond., 12, 162

Weber. F. Parkes (1922). Right-sided hemi-hypotrophy resulting from right-sided congenital spastic hemiplegia, with a morbid condition of the left side of the brain, revealed by radiograms. J. Neurol. Psychopath., 3, 134

(1929). A note on the association of extensive haemangiomatous naevus of the skin with cerebral (meningeal) haemangioma, especially cases of facial vascular naevus with contralateral hemiplegia. Proc roy. Soc. Med., 22, 431.

(1936). The Sturge-Kalischer disease, and the Sturge-Weber (1936). The Sturge-Kalischer disease, and the Sturge-W

Wohlwill, F. J. and Yakovlev, P. I. (1957). Histopathology of meningo-facial angiomatosis (Sturge-Weber's disease): Report of four cases. J. Neuropath. exp. Neurol., 16, 341. 